\title{
"POESIA COM GOSTO DE SANGUE E MEL": HISTÓRIA, MEMÓRIA E METALINGUAGEM EM RASTROS DE RESISTÊNCIA
}

\author{
"POESÍA CON SABOR DE SANGRE Y MIEL": HISTORIA, MEMORIA Y \\ METALINGÜE EN HISTORIAS DE RESISTENCIA
}

\begin{abstract}
"POETRY WITH BLOOD AND HONEY TASTE": HISTORY, MEMORY AND METALANGUAGE IN RESISTANCE TRACKS
\end{abstract}

DOI: $10.22481 /$ rbba.v10i01.8744

Esmeralda Guimarães Meira Universidade do Estado da Bahia - Campus VI/Caetité, Bahia, Brasil ID Lattes: http://lattes.cnpq.br/9305447162441237 ORCID: https://orcid.org/0000-0001-6553-4570. Endereço eletrônico: emeira@uneb.br

Fernanda Pessoa Barbosa ${ }^{\mathrm{i}}$ Universidade do Estado da Bahia-Campus VI/Caetité, Bahia, Brasil ID Lattes: http://lattes.cnpq.br/4467346530019242 ORCID: https://orcid.org/0000-0001-7133-8373 Endereço eletrônico: nandabarbosa012@gmail.com

\section{RESUMO}

Este texto tem como objetivo investigar a (meta)linguagem poética e a relação apresentada entre memória, história e literatura em textos literários do escritor baiano Camillo de Jesus Lima. O corpus para este recorte é formado por dois poemas do autor: "Que o coração diga tudo" e "A um Parnasiano", integrantes do livro Cantigas da Tarde Nevoenta (1955). Para tanto, são utilizadas fontes bibliográficas, sob o enfoque teórico-metodológico do materialismo histórico-dialético. Alguns autores subsidiam 
tanto os estudos teóricos como metodológicos: Bosi (2000; 2015;2017), Candido (2006), Chalhub (2005), Halbwachs (1990), Hobsbawm (2013) Le Goff (1990) e Marx; Engels (2010). Destarte, os poemas conduzem em suas linhas e entrelinhas duras críticas ao alheamento, à insensibilidade e ao distanciamento da realidade. Sejam nos versos líricos e suaves de "Que o coração diga tudo", seja na rispidez e rebeldia de "A um Parnasiano", são expressos os ideais de luta contra a desumanidade, contra as ideologias dos grupos sociais hegemônicos. A lírica moderna, ao voltar sobre si, procura manter claros os seus objetivos, a sua missão, seu descontentamento com os rumos da história.

Palavras-Chave: Memória e História; Literatura; Camillo de Jesus Lima; Metalinguagem.

\section{RESUMEN}

Este texto tiene como objetivo investigar el lenguaje (meta) poético y la relación que presentan la memoria, la historia y la literatura en los textos literarios del escritor bahiano Camillo de Jesús Lima. El corpus de este recorte está formado por dos poemas del autor: "Que el corazón lo diga todo" y "A un parnasiano", parte del libro Cantigas da Tarde Nevoenta (1955). Para ello se utilizan fuentes bibliográficas, bajo el enfoque teórico-metodológico del materialismo histórico-dialéctico. Algunos autores apoyan estudios tanto teóricos como metodológicos: Bosi (2000; 2015; 2017), Candido (2006), Chalhub (2005), Halbwachs (1990), Hobsbawm (2013) Le Goff (1990) y Marx; Engels (2010). De esta forma, los poemas conducen en sus líneas y líneas duras críticas a la alienación, la insensibilidad y el alejamiento de la realidad. Ya sea en los versos líricos y suaves de "Que el corazón lo diga todo", o en la dureza y rebeldía de "A un parnasiano", se expresan los ideales de lucha contra la inhumanidad, contra las ideologías de los grupos sociales hegemónicos. La lírica moderna, al volver sobre sí misma, intenta mantener claros sus objetivos, su misión, su descontento con el rumbo de la historia.

Palabras clave: Memoria e Historia; Literatura; Camillo de Jesus Lima; Metalenguaje.

\section{ABSTRACT}

This text aims to investigate the (meta) poetic language and the relationship presented between memory, history and literature in literary texts by the Bahian writer Camillo de Jesus Lima. The corpus for this clipping is formed by two poems by the author: "Que o coração diga tudo" and "A um 
Parnasiano", part of the book Cantigas da Tarde Nevoenta (1955). For this, bibliographic sources are used, under the theoretical-methodological approach of historicaldialectical materialism. Some authors support both theoretical and methodological studies: Bosi (2000; 2015; 2017), Candido (2006), Chalhub (2005), Halbwachs (1990), Hobsbawm (2013) Le Goff (1990) and Marx; Engels (2010). In this way, the poems lead in their lines and hard lines critical to the alienation, insensitivity and to distancing from reality. Whether in the lyrical and soft verses of "May the heart say everything", or in the harshness and rebelliousness of "A um Parnasiano", the ideals of fighting against inhumanity, against the ideologies of the hegemonic social groups are expressed. The modern lyric, when returning on itself, tries to keep its objectives, its mission, its discontent with the history direction.

Keywords: Memory and History; Literature; Camillo de Jesus Lima; Metalanguage.

\section{LITERATURA, HISTÓRIA, MEMÓRIA...}

O movimento da linguagem poética percorre séculos e séculos sem se esgotar e é o que inspira a feitura deste trabalho acerca da produção literária do escritor baiano Camillo de Jesus Lima. O corpus de análise é formado por dois poemas da lavra do autor: "A um Parnasiano" e "Que o coração diga tudo", integrantes do livro Cantigas da Tarde Nevoenta, escrito em 1940 e publicado em 1955.

A pesquisa tem como objetivo investigar a (meta)linguagem poética e a relação apresentada entre memória, história e literatura em textos literários do poeta em estudo. Desse modo, faz-se necessário compreender as relações entre os conceitos e a construção dos sentidos nos textos camilianos; as motivações, imagens e perfis construídos pelo autor, contidos no movimento entre a obra e o contexto social em que se insere.

Compreende-se a importância desse estudo tanto no que se refere aos diálogos entre literatura, memórias e histórias - que se transformam a cada novo tempo, a cada sujeito - quanto aos estudos e trabalhos sobre o escritor Camillo de Jesus Lima, seu papel na literatura nacional, seu lugar ao lado dos párias. Pode-se dizer que muito pouco foi estudado sobre ele, diante da diversidade e amplitude de seus escritos. Muito ainda precisa ser dito para que sua obra seja valorizada e devidamente conhecida. 
"POESIA COM GOSTO DE SANGUE E MEL": HISTÓRIA, MEMÓRIA E METALINGUAGEM EM RASTROS DE RESISTÊNCIA

Para a realização deste trabalho são utilizadas fontes primárias, analisadas sob o enfoque teórico-metodológico do materialismo histórico-dialético, partindo da historicidade dos fenômenos e dos sujeitos internos e externos aos textos, em suas condições concretas na sociedade, relacionando o ficcional com o factual.

Alguns autores subsidiam os estudos teóricos e metodológicos de linha marxista em diálogo com outros estudos basilares à pesquisa: Bosi (2000), Chalhub (2005), Candido (2006), Halbwachs (1990), Hobsbawm (2013), Le Goff (1990), Marx; Engels (2010), como também leituras e análises do material empírico: poemas, crônicas, entrevistas. Todos os dados obtidos foram pautados no movimento dialético da literatura com os demais conceitos pertinentes, já elencados acima, em especial o de história e de sociedade.

A literatura - arte da palavra - é expressão permeada por encontros: do escritor com a criatividade, com o mundo, seus anseios, ideologias, como um sujeito histórico e social, que sente as tensões do seu tempo. O encontro também se realiza no diálogo do leitor com o texto e, através dele, do leitor com o escritor.

Dos encontros no texto literário se confluem tanto aspectos internos (da própria estrutura) quanto externos (sociais, psicológicos, econômicos, culturais, existenciais). Estes elementos, considerados inicialmente, externos tornam-se, por sua vez, também internos, na dinâmica da obra, pois, como explica Candido (2006, p. 34), a literatura é um organismo em que se percebe "o movimento dialético que engloba a arte e a sociedade num vasto sistema solidário de influências recíprocas".

Segundo Lucáks (2010, p. 13), a “essência e o valor estético das obras literárias, bem como a influência exercida por elas, constituem parte daquele processo geral e unitário através do qual o homem se apropria do mundo através de sua consciência”. Nesse sentido, é preciso compreender que os indivíduos, em sua maioria, são movidos por suas necessidades materiais e as possibilidades existentes, na maioria das vezes, são impostas pelos grupos sociais hegemônicos. Na sociedade capitalista, a base econômica constitui-se como condicionante das relações sociais e, a partir dela, se ergue a superestrutura. Conforme sintetizam Marx e Engels, base e superestrutura unem-se e se influenciam reciprocamente:

O desenvolvimento político, jurídico, filosófico, religiosos, literário, artístico etc. se funda no desenvolvimento econômico. Mas estes elementos interagem entre si e reatuam também sobre a base econômica. Não é que a situação econômica seja a causa, e a única atuante, enquanto todo o resto seja efeito 
"POESIA COM GOSTO DE SANGUE E MEL": HISTÓRIA, MEMÓRIA E METALINGUAGEM EM RASTROS DE

RESISTÊNCIA

passivo. Ao contrário, há todo um jogo de ações e reações à base econômica, que, em última instância, sempre se impõe. (MARX; ENGELS, 2010, p. 105).

Vê-se que os indivíduos não são livres e neutros, pois até mesmo sua consciência é determinada pelas relações sociais que os cercam. Nesse sentido, a literatura, como produto humano, interage com o movimento, a evolução e o desenvolvimento social e histórico. A palavra, carregada de imagens e sentidos, faz-se e refaz no jogo com o mundo real e concreto, com o ser social, com a consciência dos indivíduos e possui grande força frente às contradições da sociedade capitalista.

Desse modo, os aspectos externos não se sobrepõem à estrutura da obra ou à criatividade do autor, eles apresentam-se como elementos necessários na dinâmica literária. Candido (2006, p. 28) menciona Sainte-Beuve para explicitar o diálogo do escritor com o meio, e mesmo sendo este elemento determinante na criação, é na relação com o contexto histórico e toda a significação que a vida ganha, que a obra é gerada: “O poeta não é uma resultante, nem mesmo um simples foco refletor; possui o seu próprio espelho, a sua mônada individual e única. Tem o seu núcleo e o seu órgão, através do qual tudo o que passa se transforma, porque ele combina e cria ao devolver à realidade".

A literatura também possui imbricações com a memória, tanto individual quanto coletiva, porque aquele que escreve viveu em um período, sentiu as tensões políticas, religiosas, filosóficas, sociais daquele momento, carrega memórias formadas a partir de suas próprias experiências, mas também as que foram compartilhadas e vividas com os que estavam a sua volta. Para Le Goff (1990, p. 477) a memória, “onde cresce a história”, é um elemento fundamental da identidade de cada indivíduo e de uma sociedade em suas estruturas e superestruturas. Ela não está estagnada, porque é um organismo que se constrói e reconstrói com o movimento dos tempos e das mentalidades de cada época. A memória tem como propriedade "conservar certas informações" (p. 423) essenciais para a identidade e memória coletivas, sendo assim formada pelas relações entre passado, presente e futuro, que, como explica Hobsbawm (2013), constituem um continuum de interações.

No fazer literário confluem-se aspectos históricos, sociais, da memória individual e coletiva, porque aqueles que leem e escrevem estão em sociedade, guardam em si as culturas, ideologias, sentimentos, emoções, dores compartilhadas com os outros indivíduos.

Em vista disso, chama-se atenção para o autor em pauta. Toda a produção literária de Camillo de Jesus Lima está impregnada de experiências, seja como professor, oficial de 
"POESIA COM GOSTO DE SANGUE E MEL": HISTÓRIA, MEMÓRIA E METALINGUAGEM EM RASTROS DE RESISTÊNCIA

cartório, secretário municipal, boêmio ou militante das causas sociais. Em 2012 comemorou-se o seu centenário de nascimento, a 08 de setembro de 1912, na cidade de Caetité, Alto Sertão da Bahia, filho de Esther Fagundes da Silva e Francisco Fagundes de Lima. Foi autor de crônicas, poemas, contos, romances, fez traduções, resenhas e críticas de rodapé. Ele contribuiu com muitos jornais da época, em Vitória da Conquista, cidade que adotou como segunda terra-mãe, em Salvador e fora do Estado da Bahia. Camillo de Jesus Lima não chegou a ingressar na vida acadêmica, mas aprendeu com o pai, desde cedo, a importância da leitura dos livros e do mundo.

Tratando-se da produção poética, Camillo de Jesus Lima publicou em vida os livros Poemas, Novos Poemas, As Trevas da Noite Estão Passando (em colaboração com Laudionor Brasil), A Mão Nevada e Fria da Saudade, Cantigas da Tarde Nevoenta, Viola Quebrada, O Livro de Miriam e Di-versos, reunidos e (re)publicados em dois volumes pela Assembleia Legislativa do Estado da Bahia, em uma edição de 2014, da qual foram retirados os poemas que serão analisados.

\section{METALINGUAGEM EM RASTROS DE RESISTÊNCIA}

Os poemas "Que o coração diga tudo" e "A um Parnasiano" fazem parte do livro Cantigas da tarde nevoenta, produção datada da década de 1940, com primeira edição em 1955. Assim, iniciam-se os versos do primeiro poema, que possui doze estrofes, dez delas com quatro versos e as outras com cinco e seis versos.

Quando na tua mão suspenderes a pena

Para o ofício maior de versejar,

Brote dela a verdade, impávida e serena,

Como uma fonte clara e límpida a jorrar.

Se o luar não se embebeu no teu olhar nevoento,

Se para o céu tu nunca abriste o teu olhar,

Nunca fales de céu, nem de luar,

Pois teus versos serão ermos de sentimento.

Se nunca amaste, não profanes nunca A poesia, a falar de paixões mentirosas; Jamais digas que a dor a tua estrada junca Se calcas aos teus pés um tapete de rosas.

Seja a verdade o teu dilema, o teu mister.

Nada mais te adianta. Que há de ser de

Ti, que ainda crês morar a fama na cor verde

Da cabeleira, como Baudelaire? (LIMA, 2014, p. 45). 
"POESIA COM GOSTO DE SANGUE E MEL": HISTÓRIA, MEMÓRIA E METALINGUAGEM EM RASTROS DE RESISTÊNCIA

Logo no início, percebe-se um jogo com a linguagem: o eu lírico questiona sobre o processo criador e aponta o caminho que o leitor-poeta deverá seguir. Na construção da linguagem poética destaca-se a função metalinguística, a poesia olhando para si. Segundo Chalhub (2005, p. 32), “a função metalinguística, em síntese, centraliza-se no código: é código 'falando' sobre código [...], é linguagem ‘falando' de linguagem”. E em “Que o coração diga tudo", o seu autor extrapola esta condição metalinguística apontada pela teórica e avança para a condição de que o código está imbuído de uma opção semântica, política e ideológica. Ou seja, deixa claro que ao falar da feitura poética traz nessa ação uma responsabilidade estética, política e social.

O percurso de escrita sugerido pelo eu lírico aponta que se deve prezar pela "verdade", "clara e límpida"; inspira a busca por uma verdade que parte do real, da experiência, caso contrário, as palavras do poema não passariam de falácias ou puro sentimentalismo: "Se o luar não se embebeu no teu olhar nevoento, /Se para o céu tu nunca abriste o teu olhar, / Nunca fales de céu, nem de luar, / Pois teus versos serão ermos de sentimento" (LIMA, 2014, p. 45). O eu poético propõe que estas experiências concretas representadas como capazes da "verdade" partem da vivência dos indivíduos no mundo. Esta verdade não está submetida exclusiva e puramente ao eu poético, porque tratam-se de níveis de uma "verdade literária" em que entram em diálogo o individual e o coletivo.

As experiências individuais estão carregadas de coletividade: recordações, lembranças, encontros, momentos, impulsos, pensamentos, esquecimentos, que se (re)constroem em sociedade, na troca com o outro. $\mathrm{O}$ entendimento sobre as interações individuais e coletivas remonta aos estudos de Halbwachs (1990) em seu livro Memória coletiva. Segundo o autor, é comum os indivíduos atribuírem certos pensamentos, reflexões, ideias, paixões e convicções a si mesmos, a sua própria memória individual. Todavia, muitas dessas atribuições são, na verdade, construídas socialmente, são herdadas e apoiadas na sociedade a qual o sujeito pertence. Mesmo que o ser social pareça sozinho a um primeiro olhar, ele é impulsionado pelo seu grupo e pela memória coletiva a adotar ou rejeitar determinado comportamento, visto que “[...] lá não esteve só senão na aparência, posto que, mesmo nesse intervalo, seus pensamentos e seus atos se explicam pela natureza de ser social, e que em nenhum instante deixou de estar confinado dentro de alguma sociedade" (HALWACHS, 1990, p. 36-37).

Dessa forma, imbricam-se as memórias individuais e coletivas na produção literária e na vida real. As memórias não estão separadas, como se formassem conjuntos diferentes e se 
"POESIA COM GOSTO DE SANGUE E MEL": HISTÓRIA, MEMÓRIA E METALINGUAGEM EM RASTROS DE

RESISTÊNCIA

constituíssem de forma independente, pois estão imbricadas, em constante dialogo, "e o que vai garantir esse diálogo, essa vontade de memória, é a compreensão histórica em cada tempo e lugar". (MEIRA, 2017, p. 77).

Pode-se perceber que as memórias materializadas e (re)construídas pelo sujeito poético vão além de suas próprias emoções pessoais, em um movimento dialético, fruto do seu ser social. Essas interações entre o eu literário e a vida possuem marcas do encontro do autor Camillo de Jesus Lima com o mundo. Do interior da Bahia, sentiu, sofreu e exprimiu as convulsões e os sentimentos de sua época, rastros de guerras, ditaduras e das vidas sofridas no Brasil e no mundo. Segundo Meira (2017, p. 36), “a história da humanidade era a sua própria história”.

\begin{abstract}
A representação não se volta apenas para os sentimentos pessoais de um eu, mas se amplia como expressão de um momento da humanidade. Trata-se de uma época marcada pelo profundo "sentimento de mundo", expressamente difundido por Drummond em A rosa do povo e tal qual o poeta mineiro, Camillo de Jesus Lima remete a todos à experimentação de profundas perplexidades, ante os desafios sociais, políticos e existenciais. (MEIRA, 2010, p. 62).
\end{abstract}

Nos versos seguintes, a função atribuída ao poeta é a de "cantar as mágoas", as dores, de ser a voz que desperta para a realidade "dos que não têm alma". Os impiedosos, que não se padecem com os sentimentos alheios devem ser tocados pela verdade da poesia:

Poeta, o teu ofício é contar a verdade;

Cantar as mágoas como uma ave calma,

Para que as almas dos que não têm alma

Ganhem, um dia, o grande dom de ter piedade.

Teu ofício é fazer vibrar fibra por fibra

O coração de alguém que nunca soube amar.

E, chorando, ensinar - alma de harpa que vibra,

Aos que não choram nunca a graça de chorar.

Quando, na tua mão, suspenderes a pena

Para a glória maior de versejar,

Brote dela a piedade - a linfa clara e amena,

Branca, de alvo palor, doce como luar.

Um dia hão de te ler. Se mentires no ofício,

A esmo dizendo o que não tens no coração,

Ler-te-ão na algidez da fria indiferença;

Nunca terás o pranto em recompensa,

Nunca terás em recompensa a gratidão. 
E de que te valeu tão duro sacrifício?

Mas, se fores sincero, um dia, alguém

Que te há de ler tendo nos olhos a ansiedade,

Sentirá mais profunda e mais triste a saudade

- Fada boa que traz nas mãos do mal um bem.

E, entre teus versos, acharás, um dia,

Uma pálida pétala fanada,

- Lembrança da alma que te leu, amargurada,

Quando o sol, triste e pálido, morria.

Tantos versos de dor tu deixaste dispersos!

Acharás - prêmio bom ao tormento infinito -

A nódoa de uma lágrima entre os versos

Que arrancaste a chorar do coração aflito.

Por isso, Poeta, escuta: Quando a pena

Tu suspenderes para versejar,

Dela brote a verdade, impávida e serena;

Dela mane a piedade, - a linfa clara e amena,

Branca, de alvo palor, doce como o luar... (LIMA, 2014, p. 45-46).

Um pulsar rítmico preenche os espaços entre os versos do poema. A musicalidade advinda das rimas consoantes transmite uma suavidade e uma cadência harmoniosa às palavras. A fluidez dos sons embala a associação de imagens produzidas sobre o conceito de "Verdade", assim como a reiteração na primeira, na sétima e na décima segunda estrofes de palavras como impávida, serena, fonte clara, límpida, linfa clara, branca, alvo palor, doce, luar, que evocam sentidos de pureza, brandura, docilidade.

$\mathrm{Na}$ oitava estrofe do poema, o eu lírico suscita a imagem do ato de escrever como um sacrifício, uma dor, que terá por recompensa o "pranto", "a gratidão", a epifania de seus leitores ao encararem a "verdade". A palavra, à procura do seu valor, encontra a verdade, que se revela virtuosa, transbordando coragem, mansidão, afabilidade e, em especial, a piedade, "a linfa clara e amena / branca, de alvo palor, doce como luar".

O poeta sofre porque sente como se fossem suas as dores escritas; o poeta sofre, pois antes que a palavra chegue a ser lançada no papel ao encontro do leitor, ela já encontrou morada em seu coração. Entretanto, a dor, como sugere Fernando Pessoa em seu poema "Autopsicografia" de 1931, não deixa de ser fingimento. Fingir, neste sentido, não significa dissimulação ou mentira; é a capacidade do poeta de sentir, de transmitir sentimento, não aquele que o poeta teve ao escrever, mas a dor e a emoção transmitidas em suas palavras ao leitor. 
"POESIA COM GOSTO DE SANGUE E MEL": HISTÓRIA, MEMÓRIA E METALINGUAGEM EM RASTROS DE RESISTÊNCIA

O lirismo abundante em "Que o coração diga tudo" dá lugar à aspereza e à rigidez de “A um parnasiano", também integrante do livro Cantigas da tarde nevoenta de 1940, considerado por muitos críticos como uma obra de transição do autor, de uma fase literária para outra. Embora o escritor Camillo de Jesus Lima não se prenda a um movimento literário específico - ao contrário, transita pelo romantismo, parnasianismo, simbolismo, modernismo essa obra pode demarcar um período de transição pela ênfase dada às características do movimento modernista brasileiro.

\section{A UM PARNASIANO}

Não tenho, como tu', a alma de grego.

Tenho a alma de um bárbaro indômito,

Crestada de sol, batida das intempéries.

Não posso levar minhas emoções para a casa, como tu fazes,

Porque eu não resistiria trazer dentro de mim essa tormenta,

E explodiria, com certeza, si guardasse dentro de mim esse vulcão imenso

Minha poesia vem como o anátema dos profetas:

Indômita, louca, sem peias, desatinada.

Salta na mesa do café. Sobe com a fumaça do meu cachimbo.

Brilha na espuma da cerveja,

Sai dos meus lábios, ríspida e bárbara, como os meus gritos de amor e sofrimento. (LIMA, 2014, p. 69).

Os versos se iniciam como uma conversa, um diálogo em que o eu lírico define a essência do seu ser como revolta, um vulcão prestes a explodir, alma indomável, "crestada de sol", "batida de intempéries", que não guarda emoções, dores, desesperanças em si, mas que transborda nos versos de sua poesia. Versos marcados por feridas, angústias, amarguras e injustiças. Poesia “indômita", "louca”, "sem peias", "desatinada".

A revolta, a angústia e a força descritas como necessárias ao fazer literário são transmitidas também pela própria estrutura do poema: ora pelos versos longos, sem rimas, ora pelas frases curtas e declarativas, tecendo imagens de obstinação, firmeza e rigidez.

O parnasianismo, movimento literário suscitado nos versos, segundo Bosi (2017, p. 233), é marcado pela "objetividade no trato dos temas e o culto da forma [...], o gosto da descrição nítida (a mimese pela mimese), concepções tradicionalistas sobre metro, ritmo e rima e, no fundo, o ideal da impessoalidade", ideais estes contrários aos defendidos pelo eu lírico camilliano. A poesia engajada com o social, como sugerida no poema, dá vazão aos sentimentos, não escondem as convulsões que atormentam, afastando-se do poeta parnasiano. 
"POESIA COM GOSTO DE SANGUE E MEL": HISTÓRIA, MEMÓRIA E METALINGUAGEM EM RASTROS DE RESISTÊNCIA

Entretanto, não significa o desprezo ao parnasianismo, mas, sim, sugere uma crítica ao esvaziamento da palavra, da sua conexão e do seu entrelaçamento com o mundo. Meira (2010, p. 56) defende que “o texto 'A um parnasiano' explicita crítica não ao parnasianismo, mas ao parnasiano Camillo de Jesus Lima - poeta que anteriormente fez uso das formas clássicas, utilizando-se de métricas e rimas, recursos agora olhados com restrições”.

Os versos seguintes do metapoema continuam conduzidos pela discussão da própria essência da poesia e do seu papel:

Eu tenho todas as dores humanas dentro de mim:

Gritam operários caídos dos andaimes.

Gemem meninos com fome.

Abençoam mães martirizadas.

Amaldiçoam prostitutas bêbadas.

Que rima em acharia para essa tormenta poética?

Que metros meus dedos poderiam contar para esse turbilhão emotivo?

Não. Minha poesia não é como a tua, a flor cuidada nos interiores silenciosos.

Minha poesia é aquele cardo selvagem de Manuel Bandeira,

Que as mãos dos homens nunca podem tornar delicado.

Não tenho, com tu, a alma de grego.

Tenho a alma de mongol.

Não nasci vendo o céu sereno e o mar azul.

Nasci recebendo na face a chicotada da neve das estepes imensas.

Tu contornas teus versos de mármore com o cinzel delicado.

Como se fizessem colunas para salões fidalgos.

T'u facetas teus versos de ouro com o buril.

Como se eles fossem um mimo de Celini para as mãos das princesas.

Os meus versos eu os atiro a esmo nas faces dos maus.

São blocos de pedras que eu tiro da alma, com marteladas fortes,

Para construir, com a argamassa do sangue e das lagrimas,

$\mathrm{O}$ grande monumento, disforme e rude, ao sofrimento universal.

Não. Eu não tenho, como tu, a alma de grego. (LIMA, 2014, p. 69-70).

Quando, na quarta estrofe, o sujeito poético declara guardar todas as dores humanas dentro de si, faz uso de verbos no presente do indicativo (gritam, gemem, abençoam, amaldiçoam), marcas de uma ação presente no momento da fala. Logo, pode-se sugerir que vozes ainda ecoam de seus versos, se atualizam nos lábios, nas linhas, nas imagens daqueles que guardam o "sentimento do mundo", como diria Drummond.

Guardar "todas as dores humanas" dentro de si não parece ser tarefa fácil, nem mesmo é possível esconder as emoções e revoltas que esperam à porta do poeta para serem reescritas nos versos. Poesia que carrega vozes e memórias silenciadas, de suor e sangue, não belas 


\section{"POESIA COM GOSTO DE SANGUE E MEL": HISTÓRIA, MEMÓRIA E METALINGUAGEM EM RASTROS DE RESISTÊNCIA}

paisagens ou a suavidade da vida. Nesse sentido, assim como no poema "Que o coração diga tudo", são evocadas as imagens e memórias que o sujeito poético compartilha com o mundo a sua volta, traçando os rastros da resistência e as marcas de uma literatura que tem como propósito ser social.

Além do parnasianismo, também é presente a poesia grega, notável por seu lirismo, objetividade, entrelaçamento entre o humano e o divino, a sensualidade, palco dos grandes mitos e temas. Entretanto, o eu lírico aponta à poesia um caminho diverso, guiado não pelo mármore, ouro, nem para "as mãos das princesas". Sua escrita é produzida com a força e a firmeza de "blocos de pedras", "com a argamassa de sangue e das lágrimas", para uma construção específica: o monumento "ao sofrimento universal", o que permite transparecer a consciência de classe do sujeito poético e sua escolha em lutar ao lado dos humildes e marginalizados.

A construção do "grande monumento, disforme e rude, ao sofrimento universal" se constrói com a luta, e é também uma forma de documentar a história da sociedade. E conforme define Le Goff (1990, p. 535): “Atendendo às suas origens filológicas, o monumento é tudo aquilo que pode evocar o passado, perpetuar a recordação, por exemplo, os atos escritos."

A escrita metalinguística de forte militância e engajamento social é própria de Camillo de Jesus Lima, o que, respeitando o espaço entre autor e obra, é demonstrado nos versos de seus poemas. Ao poeta cabe contar a verdade, tocar o coração dos insensíveis, ser porta-voz dos sofredores, posicionar-se criticamente frente às tormentas da história. Segundo Meira (2017, p. 38), "para ele, a arte deveria refletir a experiência humana, e o poeta que não representasse os verdadeiros sentimentos da humanidade, suas contradições, suas dores, seria apenas um mero fazedor de versos". Camillo de Jesus Lima, assumindo-se como um intelectual de esquerda, viveu como um verdadeiro "ator social da história".

$\mathrm{Na}$ cidade de Conquista, onde a tragédia humana me ensanguentou a sensibilidade, comecei a compreender que a minha arte devia ter outra finalidade. Devia esquecer o mundo das emoções subjetivas e ter uma função social. Lembrei-me então das palavras de Mathews Arnold: a poesia deve ser uma crítica da vida, e achei razão na sentença de Wordsworth: a poesia é uma atitude do espírito diante dos fenômenos da existência. Deixei de ser um místico da beleza e fiz da arte uma arma de combate. (LIMA apud MEIRA, 2017, p.131, grifo nosso).

A comparação da arte como uma "arma de combate" é expressiva e fundamental para se compreender a escrita camilliana, que se preocupou em estar em posição de batalha contra a 


\section{"POESIA COM GOSTO DE SANGUE E MEL": HISTÓRIA, MEMÓRIA E METALINGUAGEM EM RASTROS DE RESISTÊNCIA}

realidade opressora e seus produtores e ao lado os pobres, dos proletários, das mulheres, dos humildes e de todos aqueles que compartilhassem do seu ideal.

O escritor em estudo dedicou-se assiduamente à leitura das obras de Karl Marx e viu no materialismo uma nova concepção, um método para compreensão dos fenômenos sociais e da literatura como um grande instrumento de conscientização e de discussão sobre temáticas sociais, como a desigualdade, guerras, pobreza, política e cultura. Em carta a um amigo, relata:

[...] estou estudando muito o marxismo; estou fazendo, mesmo, modéstia à parte, uma grande cultura marxista, que hei de empregar, em melhores dias, a serviço do glorioso partido do proletariado. [...] Dia a dia me aprofundo mais na doutrina de Marx, - esse gênio que conseguiu criar não apenas um sistema filosófico, porém, toda uma concepção de vida, - norte à solução única do complicado problema social e humano. ${ }^{\text {ii }}$

Camillo dedicava-se à leitura dessa nova concepção teórico-metodológica que buscava aplicar na vida e na sua produção literária. Cada vez mais consciente das condições sociais imposta por uma sociedade capitalista e classista, conduzia suas leituras com crítica, misturando razão e emoção. Cada vez mais voltava seu olhar para a história da humanidade, as relações de produção, a exploração de uma classe proletária e tudo isso interferiu na construção de uma literatura que não se resumia na beleza estética, mas indo ao encontro do homem como "ator social da história" e sujeito de transformação.

Desse modo, pode-se compreender melhor o papel da metalinguagem em muitos de seus poemas e a relação dialética que possui sua escrita com a vida, afinal, a metalinguagem, conforme explica Chalhub é um signo da modernidade, pois ela se insere no movimento de evolução e desenvolvimento da história, das sociedades, da cultura e do próprio conceito de arte e literatura, fruto da Revolução Industrial e suas consequências. Para a autora, um referencial importante desse elemento estético diz respeito ao fato de a metalinguagem reforçar a ideia da "perda da aura, uma vez que dessacraliza o mito da criação, colocando a nu o processo da produção da obra" (CHALHUB, 2005, p. 42).

Conforme explanação de Bosi (2000, p. 164), por muito tempo difundiu-se o "mito da criação", em que o poeta era visto como um ser especial, único, era o escolhido, dotado da capacidade de doar sentido, de unir, de transformar a palavra. A partir do desenvolvimento do "estilo capitalista e burguês de viver", no século XVIII, objetos e almas são inseridos no processo que transforma tudo em mercadoria. Perde-se o mito da criação na qual estava envolta 


\section{"POESIA COM GOSTO DE SANGUE E MEL": HISTÓRIA, MEMÓRIA E METALINGUAGEM EM RASTROS DE RESISTÊNCIA}

a arte, a relação divino/humano que pertencia ao poeta. Seu valor passa a ser definido por sua posição hierárquica na sociedade dividida em classes e status.

Passou-se a discutir o próprio sentido e o valor estético da arte e da literatura que, reduzidas à mercadoria, perdiam-se. Como elucida o crítico literário, a sociedade teve sua realidade mascarada e encoberta pela ideologia dominante, que buscou passar por natural as divisões sociais e suas reais contradições, justificando-as "sob nomes vinculantes como Progresso, Ordem, Nação, Desenvolvimento, Segurança, Planificação e até mesmo (por que não?) Revolução”. (BOSI, 2000, p. 168).

A literatura vista como mera mercadoria que atendia a uma cultura capitalista também foi criticada por Raymond Williams, destacando o valor plural que se apresenta na obra literária, em especial no Modernismo:

O burguês era o negociante e o vendedor de livros que, dentro do mercado recém-dominante, estava tratando as obras de arte como simples mercadorias, seu valor determinado pelo sucesso ou pelo fracasso nas vendas. [...] um dos pontos centrais da queixa contra esse tratamento da arte era o de que a arte criativa era mais do que um simples trabalho; seu valor cultural e espiritual, e, portanto, seu valor estético, estava sendo notadamente insultado pela forma como a redução da mercadoria se realizava. (WILLIAMS, 2011, p. 35).

Mas assim como o outro lado da história, a poesia precisa resistir, subsistir em um momento em que a palavra, antes usada para dar sentido, nomear, unir, "parece condenada a dizer apenas aqueles resíduos de paisagem, de memória e de sonho que a indústria cultural ainda não conseguiu manipular para vender" (BOSI, 2000, p. 165). Diversos caminhos foram percorridos pela "poesia-resistência", dentre eles a poesia metalinguagem como "o movimento vivo da consciência”. (p. 172). Então, a possibilidade histórica de subsistir dentro do sistema capitalista foi o da resistência:

A poesia resiste à falsa ordem, que é, a rigor, barbárie e caos, 'esta coleção de objetos de não amor' (Drummond). Resiste ao continuo 'harmonioso' pelo descontínuo gritante; resiste ao descontínuo gritante pelo contínuo harmonioso. Resiste aferrando-se à memória viva do passado; e resiste imaginando uma nova ordem que se recorta no horizonte da utopia. (BOSI, 2000, p. 169).

A linguagem poética, como parte da superestrutura e em sua relação dialética com a história e a sociedade, questiona o modelo a partir do que o poema traz: no lugar em que reina a ordem, a poesia surge com a desordem, para descentralizar, desarmonizar. A poesia como 
"POESIA COM GOSTO DE SANGUE E MEL": HISTÓRIA, MEMÓRIA E METALINGUAGEM EM RASTROS DE RESISTÊNCIA

resistência propõe, assim como nos versos do poema, ser "ríspida", "bárbara", "indômita, louca, sem peias, desatinada".

Adorno (2003) também ressalta o papel profundo da lírica no seio dessa sociedade: o de revelar aquilo que a ideologia da classe dominante naquele período procurou esconder, partindo do saber que está dentro do próprio texto literário.

Mesmo aquelas composições líricas nas quais não se imiscui nenhum resíduo da existência convencional e objetiva, nenhuma materialidade crua, as mais altas composições conhecidas por nossa língua, devem sua dignidade justamente à força com que nelas o eu desperta a aparência da natureza, escapando à alienação. A pura subjetividade dessas composições, aquilo que nelas parece harmônico e não fraturado, testemunha o contrário, o sofrimento com a existência alheia ao sujeito, bem como o amor a essa existência - aliás, sua harmonia não é propriamente nada mais que a consonância recíproca desse sofrimento e desse amor. (ADORNO, 2003, p. 70-71).

A resistência foi um elemento importante no Modernismo brasileiro. O próprio Camillo de Jesus Lima fez duras críticas ao movimento iniciado na Semana de Arte Moderna, em 1922, em sua crônica "O romantismo suplantou o modernismo na poesia contemporânea". O autor defendeu que a ênfase na estética literária não poderia, jamais, ter sobrepujado as questões de ordem social, como fez alguns dos organizadores da Semana. Todavia, Camillo encontrou no Modernismo de 30 os ideais que compartilhava: movimento cultural brasileiro marcado pela tomada de consciência dos intelectuais (especialmente de esquerda) sobre a vida e as contradições da sociedade. Este poeta baiano encontrava-se ao lado dos intelectuais que enfatizaram "questões de ordem social, local, num processo de denúncia das mazelas pelas quais passava a sociedade". (MEIRA, 2010, p. 26).

\section{ALGUMAS CONSIDERAÇÕES...}

Seus poemas metalinguísticos surgem como uma bandeira, anunciando ao mundo o ofício da escrita da vida, da morte, do sofrimento, da esperança, da utopia, que se atualizam a cada nova leitura. A lírica moderna, ao voltar-se sobre si, procura manterem claros os seus objetivos, a sua missão, seu descontentamento com os rumos da história, como explicita Chalhub (2005, p. 45), “a poesia posta-se face à necessidade de resguardar sua identidade, procura caminhos que assegurem o que é próprio dela, o que é específico”.

Os poemas estudados conduzem em suas linhas e entrelinhas duras críticas ao alheamento, à insensibilidade e ao distanciamento da realidade. Seja nos versos líricos e suaves 
"POESIA COM GOSTO DE SANGUE E MEL": HISTÓRIA, MEMÓRIA E METALINGUAGEM EM RASTROS DE RESISTÊNCIA

de "Que o coração diga tudo", seja na rispidez e rebeldia de "A um Parnasiano" são expressos os ideais de luta contra a desumanidade, contra os grupos sociais hegemônicos. Um "autor progressista", como nos termos de Benjamin (1987), em favor do proletariado, dos párias e rebeldes, estabelece na escrita o diálogo entre ficção e realidade, memória e história, marcas da consciência de classe do autor e da função estético-política que assume em sua literatura.

Os sujeitos dos séculos XX e XXI vivem as contradições em que se ergueu a sociedade capitalista, a mesma que impulsionou o surgimento da poesia-resistência, da metalinguagem e de autores que, assim como Camillo de Jesus Lima, mantém seus ideais revolucionários. O eu lírico camilliano brada que nada vale permanecer alheio e alienado, alheio às dores do mundo, aos que choram, aos que são explorados e oprimidos cotidianamente. Desse modo, a literatura assume o papel de humanizar, sensibilizar, inquietar, angustiar, desautomatizar e, a partir da práxis social, tornar-se forte instrumento de transformação. Afinal, fazer uma poesia com gosto de sangue e mel não é uma missão fácil, vestir as dores do mundo é uma tarefa revolucionária dos espíritos altruístas, como encontrada na poesia de Camillo de Jesus Lima.

\section{REFERÊNCIAS}

ADORNO, Theodor Wiesengrund. Notas de Literatura I. $1^{\text {a }}$ ed. São Paulo: Duas Cidades, 2003.

BENJAMIN, Walter. Magia e técnica, arte e política: ensaios sobre literatura e história da cultura. 7. ed. (Obras Escolhidas, v. I). Tradução Sergio Paulo Rouanet. São Paulo: Brasiliense, 1987.

BOSI, Alfredo. Entre a literatura e a história. 2a ed. São Paulo: Editora 34, 2015.

História Concisa da Literatura Brasileira. 51ª ed. São Paulo: Cultrix, 2017.

O ser e o tempo da poesia. $6^{\text {a }}$ ed. São Paulo: Companhia das Letras, 2000.

CANDIDO, Antonio. Literatura e Sociedade. $9^{a}$ ed. Rio de Janeiro: Ouro sobre Azul, 2006.

CHALHUB, Samira. A Metalinguagem. São Paulo: Ática, 2005.

HALBWACHS, Maurice. A Memória Coletiva. São Paulo: Edições Vértice, 1990.

HOBSBAWM, Eric. Sobre história. São Paulo: Companhia das Letras, 2013.

LE GOFF, Jacques. História e memória. Trad.: Bernardo Leitão et al. Campinas: Editora da UNICAMP, 1990.

LIMA, Camillo de Jesus. Obra Poética. v. 1. Salvador: Assembleia Legislativa, 2014. 
. Obra Poética. v. 2. Salvador: Assembleia Legislativa, 2014.

MARX, Karl; ENGELS, Friedrich. Cultura, Arte e Literatura (textos escolhidos). Tradução de José Paulo Neto e Miguel Makoto Cavalcanti Yoshida. $1^{\text {a }}$ ed. São Paulo: Expressão Popular, 2010.

MEIRA, Esmeralda Guimarães. O arquivista de si - história e memória do escritor Camillo de Jesus Lima. Tese (Doutorado em Memória: Linguagem e Sociedade), 205 p. Vitória da Conquista: PPMLS/UESB. 2017.

Muito além das tardes nevoentas: um estudo da lírica de Camillo de Jesus Lima. Dissertação (Mestrado) - Universidade do Estado da Bahia. Departamento de Ciências Humanas. Salvador, 2010.

WILliaMS, Raymond. Política do Modernismo. São Paulo: Editora Unesp, 2011.

NOTAS

${ }^{\mathrm{i}}$ Bolsista PICIN de Iniciação Científica.

ii Carta de Camillo de Jesus Lima a Clóvis Lima, 6.11.1946 apud MEIRA, 2017, p.156. 